\title{
Distinguishing coercion and underspecification in Type Composition Logic ${ }^{1}$ Julia LUKASSEK - University of Tübingen \\ Alexandra Anna SPALEK - University of Oslo
}

\begin{abstract}
This paper investigates the meaning adaptability of change of state $(\mathrm{CoS})$ verbs. It argues that both coercion and underspecification are necessary mechanisms in order to properly account for the semantic adaptability observable for $\mathrm{CoS}$ verbs in combination with their complements. This type of meaning adaptability has received little formal attention to date, although some recent work has already led the way on this topic (Spalek, 2014; Lukassek and Spalek, 2016; Asher et al., 2017). Our paper is part of a cross-linguistic case study of German einfrieren and Spanish congelar ('freeze'). We model the meaning adaptability of this test case within Type Composition Logic (TCL) (Asher, 2011). We build on Asher's coercion mechanism and introduce an additional mechanism for underspecification that exploits the fine-grained type system in TCL.
\end{abstract}

Keywords: lexical semantics, change of state verbs, coercion, underspecification, Type Composition Logic.

\section{Introduction}

The verbs einfrieren in German and congelar ${ }^{2}$ in Spanish ('freeze') refer to physical ((1a) and (1b)) and abstract ((2a) and (2b)) change of state events, as illustrated in the following examples. ${ }^{3}$
a. Ida fror die Suppe ein. (physical event)
Ida froze the soup in
'Ida froze the soup.'
b. Ida congeló la sopa.
Ida froze the soup
'Ida froze the soup.'
a. Die Gewerkschaft fror die Verhandlungen ein. (abstract event) the union froze the negotiations in
'The union froze the negotiations.'

\footnotetext{
${ }^{1}$ This research was supported by the SFB 833, Project A1, funded by the Deutsche Forschungsgemeinschaft. We thank the audiences of Sinn und Bedeutung 2017 and of the research seminar of the German Department of the University of Tübingen, who provided insight and expertise that greatly assisted the research, although they may not agree with all of the interpretations in this paper.

${ }^{2}$ For the purposes of this paper we will stick to German and Spanish as languages of investigation, but will illustrate our points using mainly German data. Based on the Spanish data analysed in Spalek (2014), we assume that, except for some minor differences, einfrieren and congelar display comparable behaviour.

${ }^{3}$ German examples are from Das Deutsche Referenzkorpus (DeReKo) at the Institut für Deutsche Sprache, Mannheim, available at http://www.ids-mannheim.de/kl/projekte/korpora/. Examples with no indication of the source have been constructed by us.
} 
b. El sindicato congeló las negociaciones.

the union froze the negotiations

'The union froze the negotiations.'

The wide spectrum of events referred to by einfrieren and congelar is not exclusive to German or Spanish, but rather represents a general pattern to be found in many other languages, such as, for instance, English and Polish. We will discuss how this phenomenon is to be modelled and will argue for an underspecification mechanism that generates the two basic readings from one common lexical entry. In our account, we will understand underspecification as a free combinatorial choice that is lexically anchored. In addition to these free combinatorial choices, einfrieren ('freeze') also naturally appears in coercion contexts. These contexts involve a compositional clash between the verb and its complement that can be repaired. This combinatorial option has been discussed for the physical reading in English in Asher (2011). For German, an example like (3a) involves a reinterpretation from a container to its content. (3b), in turn, is an example of such a coercion context in the abstract reading. The state-denoting argument Punktestand 'scores' is reinterpreted as a development in scores and this development can be frozen.

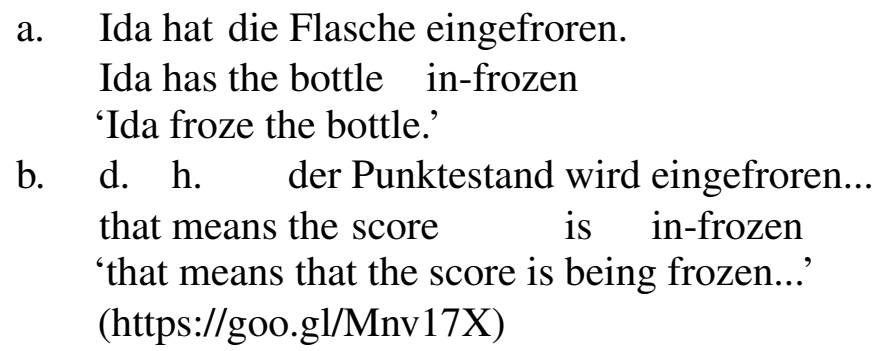

Throughout this paper, we address what characterizes the different readings of einfrieren and congelar, how their multiple meanings correlate with the semantics of their complements and what theoretical status should be assigned to the multiple readings of the verb. These questions help disentangle cases of coercion from cases of underspecification. Formally, we understand underspecification as a lexically anchored dependent type whose specification hinges on the type of a parameter contributed by the complement's type. Coercion, in turn, arises from a combinatory conflict that triggers a repair mechanism licensed by a lexical polymorphic type in the verb introducing a suitable variable.

We proceed by first providing a description of the possible readings of einfrieren and congelar, taking into account the conceptual content as well as the lexical aspectual properties. Following this, we present more data concerning the combinatorial patterns of einfrieren and congelar. Finally, we provide a semantics for einfrieren/congelar by implementing the observations in Type Composition Logic (TCL) (Asher, 2011). 


\section{Distinguishing the two readings of einfrieren}

Change of state $(\mathrm{CoS})$ verbs are generally ambiguous between referring to physical and abstract events, as already observed for Spanish by Spalek (2014). ${ }^{4}$ The reading systematically depends on the type of the internal argument.
a. Die Vase / die Beziehung zerbrach.
the vase / the relationship broke
'The vase / the relationship broke.'
b. Der Bürgermeister schnitt den Faden / die Stromversorgung ab. the mayor cut the cord / the electricity supply off 'The mayor cut off the cord / the electricity supply.'
c. Das SEK hat eine Scheibe / einen Schmugglerring zerschlagen. the SEK has a window / a trafficking ring through-smashed 'The special law enforcement unit has smashed a window / a trafficking ring.'

In order to tease apart the different readings of einfrieren, we need to take a closer look at the factors that influence the different readings. In the following, we will first examine the conceptual content contributed by the verb and, second, focus on its aspectual properties in each reading. 5

Firstly, einfrieren can describe conceptually different contents that bring about different result states. The physical reading denotes an event of change in temperature and consistency of the complement with the effect of making the complement non-perishable (5a). These properties, however, do not hold for the result state brought about by the abstract event einfrieren, as illustrated in $(5 b)$.
a. Emil fror die Suppe ein. Sie war danach kalt, steinhart und haltbar.
Emil froze the soup in she was afterwards cold, rock-hard and non-perishable 'Emil froze the soup. Afterwards it was cold, rock-hard and non-perishable.'
b. \#Die Gewerkschaft fror die Verhandlungen ein. Sie waren danach kalt, the union froze the negotiations in they were afterwards cold steinhart und haltbar.
rock-hard and non-perishable.
'The union froze the negotiations. Afterwards they were cold, rock-hard and non- perishable.'

The abstract reading, in turn, denotes an event of 'interruption'. The result state brought about by abstract einfrieren amounts to the complement event not taking place anymore, (6a). This result state does not arise in the physical reading, (6b).

\footnotetext{
${ }^{4}$ An analogous observation has been made by Asher et al. (2017: p. 137, (3)), who give possible contextual specifications for English swallow and run.

${ }^{5} \mathrm{~A}$ question that is outside the scope of this paper concerns the kinds of causation that are involved in each of the readings: issues such as direct vs. indirect causation or intentionality. These factors cut across the distinction between physical and abstract readings. For more discussion on this topic, see Spalek (2014).
} 
(6) a. Die Gewerkschaft fror die Verhandlungen ein. Sie fanden danach nicht mehr the union froze the negotiations in she took afterwards not more statt.

place

'The union froze the negotiations. Afterwards they did not take place anymore.'

b. \#Emil fror die Suppe ein. Sie fand danach nicht mehr statt.

Emil froze the soup in she took afterwards not more place

'Emil froze the soup. Afterwards it did not take place anymore.'

Abstract einfrieren has the same entailment pattern as unterbrechen 'interrupt'. Engerer (2014) (following ideas from Dowty, 1979) shows that aspectual verbs can be accounted for in terms of a common pattern of presuppositions and entailments displayed for interrupt in (7). According to these, einfrieren falls into the egressive class, like unterbrechen.

(7) Die Gewerkschaft hat die Verhandlungen eingefroren / unterbrochen.

the union has the negotiations in-frozen / interrupted

'The union froze the negotiations.'

$>>\mathrm{t}_{i-1}$ : The negotiations are going on.

$\rightarrow \mathrm{t}_{i+1}$ : The negotiations are not going on.

The two readings can be combined with two different types of modifiers. Instruments are only compatible with the physical reading, as the contrast between (8a) and (8b) illustrates, whereas only eventive mit-PPs can modify abstract readings of einfrieren, as shown in the contrast of (9a) and (9b). The fact that eventive mit-modifiers are only compatible with the abstract reading is due to the fact that these modifiers are generally restricted to events that are more abstract than the modifier event itself. They add a concrete conceptualization to their target, as observed by Lukassek (2015).

a. Ida fror die Suppe mit Flüssigstickstoff ein.

Ida froze the soup with liquid nitrogen in

'Ida froze the soup with liquid nitrogen.'

b. Die Gewerkschaft fror die Verhandlungen \#mit dem Telefon ein. the union froze the negotiations with the telephone in 'The union froze the negotiations with the telephone.'

(9) a. Die Gewerkschaft fror die Verhandlungen mit einem Telefonanruf / mit einer the union froze the negotiations with a call / with a

Pressekonferenz ein.

press conference in

'The union froze the negotiations with a call / with a press conference.'

b. Emil fror die Suppe \#mit dem Ablegen im Gefrierfach ein.

Emil froze the soup with the depositing in the freezer in

'Emil froze the soup by depositing it in the freezer.'

Physical readings of einfrieren allow embedding under perception verbs (10a), since physical events can easily be perceived by our senses. This is not natural for abstract einfrieren-events, 
as example (10b) illustrates.
a. Johann sah Emil die Suppe einfrieren.
Johann saw Emil the soup in-freeze
'Johann saw Emil freeze the soup.'
b. \#Johann sah die Gewerkschaft die Verhandlungen einfrieren.
Johann saw the union the negotiations in-freeze
'Johann saw the union freeze the negotiations.'

The observations made so far thus clearly show that abstract einfrieren readings represent overall more abstract events than the physical einfrieren-events. Clear differences are also to be observed concerning lexical aspect. Earlier studies have classified English freeze, the equivalent of German einfrieren, as a prototypical CoS verb (Levin, 1993; Levin and Rappaport Hovav, 1995; Wright, 2002; Koontz-Garboden, 2009). ${ }^{6}$ When applying classic aspectual diagnostics (Dowty, 1979), both readings of einfrieren, physical and abstract, are telic, and yet they differ with respect to Aktionsart, as the following tests illustrate: only the physical reading (11a) is compatible with interval adverbials, such as in zwei Stunden 'in two hours'.
a. Ida fror die Suppe in zwei Stunden ein.
Ida froze the soup in two hours in
'Ida froze the soup in two hours.' the union froze the negotiations in two hours in 'The union froze the negotiations in two hours.'
b. \#Die Gewerkschaft fror die Verhandlungen in zwei Stunden ein.

Only the physical reading (12a) can be embedded under the aspectual verb aufhören 'stop', since only this fulfils the requirement of having a temporal extension, whereas abstract einfrierenevents lack temporal extensions (12b).

a. Emil hörte auf, die Suppe einzufrieren, weil er doch Lust hatte, sie Emil stopped up the soup in to freeze, because he after all desire had it sofort zu essen. immediately to eat 'Emil stopped freezing the soup, because after all he wanted to eat it immediately.'

b. \#Die Gewerkschaft hörte auf, die Verhandlungen einzufrieren, weil der the union stopped up the negotiations in to freeze, because the Vorstand doch einlenkte. board after all gave in 'The union stopped freezing the negotiations, because the board gave in after all.'

The adverb fast 'almost' differs in the way it can take scope over the different readings of einfrieren. Assuming Dowty's structure of accomplishments, in the physical reading (13a) fast can scope either over the CAUSE-component or over the BECOME of the CoS, entailing that either

${ }^{6}$ See Spalek (2014) for Spanish congelar. 
Ida did not act at all or the soup did not freeze completely, respectively. The abstract reading of einfrieren (13b) displays a typical achievement behaviour with fast 'almost' conveying that the event actually did not take place and no other reading is possible.
a. Ida fror die Suppe fast ein. (2 readings)
Ida froze the soup almost in
'Ida almost froze the soup.'
b. Die Gewerkschaft fror die Verhandlungen fast ein. (1 reading) the union froze the negotiations almost in
'The union almost froze the negotiations.'

The abstract reading is furthermore hard to get in the progressive form, ${ }^{7}$ as the contrast in (14) illustrates.

\footnotetext{
a. Ida war am die Suppe einfrieren.

Ida was on the soup in-freezing

'Ida was freezing the soup.'
}

b. ?Die Gewerkschaft war am die Verhandlungen einfrieren. the union was on the negotiations in-freezing

'The union was freezing the negotiations.'

The tests above clearly illustrate that the abstract reading of einfrieren patterns together with achievements, whereas the physical reading patterns together with accomplishments. We conclude this section with the observation that the conceptual and aspectual differences are good reasons to consider the two readings as discrete. We will now turn to a more detailed analysis of the combinatorial patterns of einfrieren and congelar.

\section{Meaning contribution of the complements}

In Spalek (2014), we find a detailed description of congelar that clearly illustrates how the complement plays a crucial role in specifying the interpretation of the verb and what can be considered compositional clashes. In this section, we provide a detailed analysis of the combinatorics of einfrieren for each reading. In addition, we discuss possible lexical meanings for the two readings of einfrieren to be spelled out in TCL.

\subsection{Physical readings}

Asher (2011: 9.3) discusses two types of physical readings of English freeze. First, he describes the compositional variant that is covered by the selectional restriction LIQUID for the internal argument. This selectional restriction effectively accounts for the physical cases discussed so far. Second, he identifies a coercion reading (15) that is based on a coercion from a container to its content. The container-type noun bottle does not satisfy the selectional restriction LIQUID that

\footnotetext{
${ }^{7}$ German does not have a regular progressive. However, the dialectal Rheinische Verlaufsform corresponds to the English progressive and is standardly applied as an aspectual test.
} 
freeze imposes and thus a compositional conflict arises.

(15) The bottle froze.

The liquid in the bottle froze.

(Asher, 2011: p. 248, (9.12a))

This conflict, however, can be resolved by introducing an argument of suitable type. More precisely, within Asher's TCL, coercions have a lexical anchor insofar as compositional conflicts can be resolved via lexically encoded dependent types. The verb freeze, for instance, features a dependent type that takes a CONTAINER-type argument and yields an argument of LIQUID-type that is the content of the container. According to Asher, freeze is just one of many examples that strengthens the argument for understanding coercion as a lexically based operation.

Yet, even the restriction to liquids on the one hand and an option for coercion on the other are still too limited to account for the possible combinations in the physical domain, and examples such as in (16) and (17) prove that German einfrieren combines with all sorts of physical objects, e.g. Spargel 'asparagus' or Hagelkorn 'hailstone', that do not justify the type presupposition LIQUID. Furthermore, none of these cases plausibly involves a coercion from a container to its content.

Kann man Spargel eigentlich auch einfrieren?

can one asparagus actually also in-freeze

'Is it actually possible to freeze asparagus?'

(Im Wohnzimmer lauert das Grauen, Süddeutsche Zeitung, 22.07.2011)

Jay Lawrimore ... lobte die schnelle Reaktion der Bewohner Auroras, die das Jay Lawrimore praised the quick reaction of the inhabitants of Aurora who the überdimensionale Hagelkorn eingesammelt und eingefroren hatten.

oversized hailstone collected and in-froze had

'Jay Lawrimore, the head of the committee, praised the quick reaction of the inhabitants of Aurora, who had collected and frozen the colossal hailstone.'

(Das größte Hagelkorn war fast so groß wie ein Handball, spektrumdirekt, 05.08.2003)

Asher's proposal thus only covers a part of the combinatory potential that the physical reading of einfrieren actually displays. The two examples indicate that the selectional restriction on the internal argument is more liberal than anticipated and has to be opened to all physical objects. Thus, the mere change from a liquid to a solid state of a substance cannot be an exhaustive description of the physical reading of einfrieren. In fact, the examples discussed so far suggest that the result state of the physical reading comes in three different manifestations: 1) with liquids, like soup, the relevant change of state amounts to the physical object changing from a liquid to a solid state, 2) with solid objects, like asparagus, freezing mainly involves a reduction in their temperature, and 3) with atmospherically fragile solid objects, like hailstones, freezing essentially denotes preservation, e.g. by making sure their temperature stays below zero. We can thus conclude that for the result state of the physical reading, three component predicates have to hold of the complement, cf. (18). If a soup is frozen, its temperature is below zero, it is solid, 
and it is preserved. The same holds for asparagus and hailstone.

$$
\operatorname{frozen}_{p}(x)=\operatorname{temperature}(x)<0 \wedge \operatorname{solid}(x) \wedge \operatorname{preserved}(x) .
$$

Whereas the result state is identical in all three cases, the change of state that leads to the result differs. It might involve the change of one or more component predicates of the result. This means that the presupposition about the state of the complement before the reference time is underspecified. At least one of the three components does not apply at the time before the result state holds. Which of the components is targeted depends on the specific type of the complement.

Further, Asher's proposal for the second reading, which involves container-content-coercions, has a shortcoming too. In his account, this type of coercion is licensed by a dependent type that is anchored in the lexical semantics of freeze. His proposal predicts that the containercontent-coercion is an idiosyncrasy of freeze. However, this type of coercion appears to be very systematic and ranges over distinct verb classes, as the examples in (19) to (21) prove: all these verbs select for liquids and in all cases a container complement is acceptable. In much earlier work, Apresjan (1974) already pointed out that the container-content-metononymy is a regular polysemic pattern that can be found in many contexts.

(19) Emil hat die ganze Flasche / Tasse getrunken.

Emil has the whole bottle / cup drunk

'Emil has drunk the whole bottle / cup.'

(20) Er hat die Flasche / das Glas verschüttet.

he has the bottle / the glass spilled

'He has spilled the bottle / the glass.'

(21) Die Männer ließen sich noch eine weitere Flasche durch die Kehle laufen.

the men let self still a next bottle through the throat run

'The men swallowed yet another bottle.'

If we take Asher's endeavour to clarify the role of the lexicon in coercive operations seriously, the potential for a container-content-coercion cannot be part of the lexical entry of einfrieren. Rather, the interpretation of (15) has to be explained on independent grounds that lie outside of the scope of this paper, as they do not concern the lexical semantics of einfrieren per se.

Based on the discussion so far, we propose the lexical semantics for the physical interpretation of einfrieren in TCL-style ${ }^{8}$ in (22). Three features are central here. First, the result state of einfrieren is decomposed into the components solid, temperature below zero and preserved. We use FROZEN as a type label for these three components. Second, einfrieren selects an internal

\footnotetext{
${ }^{8}$ In TCL, meaning representations consist of two levels. The external semantics is a regular $\lambda$ term with a standard model-theoretic interpretation. The internal semantics features rich typing information on the variables of the term. It has a proof-theoretic interpretation. Both layers are integrated into one linear representation. The internal semantics is managed via an additional argument $\pi$ that stores and passes all typing information throughout the composition. Type information is concatenated by the operator $*$.
} 
argument of type P, i.e. a physical object. Third, contrary to Asher's proposal, the physical reading of einfrieren does not feature a polymorphic type that could license a container-contentcoercion.

$$
\begin{aligned}
& \llbracket \text { einfrieren }_{p} \rrbracket=\lambda \Psi \lambda \Phi \lambda e \lambda \pi \exists s . \Phi(\pi)\left(\lambda x \lambda \pi_{1} . \Psi\left(\pi_{1} * \mathrm{ARG}_{3}^{\text {freeze }}: \mathrm{P}\right)\left(\lambda y \lambda \pi_{2} .\right.\right. \\
& \text { freeze' } \left.\left.\left(e, x, y, \pi_{2} * \mathrm{ARG}_{1}^{\text {freeze }}: \mathrm{BECOME}\right) \wedge \operatorname{result}^{\prime}\left(s, e, \pi_{2} * \mathrm{ARG}_{1}^{\text {result }}: \text { FROZEN }\right)\right)\right)
\end{aligned}
$$

In the physical reading (22), einfrieren takes two generalized quantifiers, $\Psi$ (the internal argument) and $\Phi$ (the external argument), and an event variable $e$ as arguments and introduces a resultant state $s$ that is existentially bound. On the type level, einfrieren passes the type requirement $\mathrm{P}$ to its complement. The referential argument $e$ is typed as BECOME and the result state $s$ is of FROZEN-type. On the term level, einfrieren contributes a freeze'-predicate with the referential argument $e$, the internal argument $y$ and external argument $x$. The result state $s$ is related to the event $e$ via the result'-predicate. The meaning computation for sentence (23) is given in (24). This will give us a first impression of how the compositional apparatus works.

$$
\begin{aligned}
& \text { Das Mädchen fror den Tee ein. } \\
& \text { the girl froze the tea in } \\
& \text { 'The girl froze the tea.' }
\end{aligned}
$$

In (24a), einfrieren is applied to the internal argument DP den Tee. The internal argument has a standard generalized quantifier representation. It is typed as LIQUID. This typing information stems from the lexical typing of the noun Tee. The predicate selects for a physical object in this position. This type presupposition is passed onto the complement via the $\pi$-parameter, which is applied to the $\pi$-parameter within the complement DP. As liquids are subtypes of physical objects, functional application is possible and the composition proceeds. In (24b), the subject DP is integrated. As the combinatorics with the subject is of no concern here, we do not specify the type information on this argument in the interest of readability. After the subject has been integrated, the referential argument is existentially closed and type presuppositions are bound $(24 c)$.

a. $\quad$ einfrieren $\rrbracket(\llbracket$ den Tee $\rrbracket)=$

$\left[\lambda \Psi \lambda \Phi \lambda e \lambda \pi \exists e . \Phi(\pi)\left(\lambda x \lambda \pi_{1} . \Psi\left(\pi_{1} * \mathrm{ARG}_{3}^{\text {freeze }}: \mathrm{P}\right)\left(\lambda y \lambda \pi_{2}\right.\right.\right.$. freeze' $\left(e, x, y, \pi_{2} *\right.$ $\left.\mathrm{ARG}_{1}^{\text {freeze }}: \mathrm{BECOME}\right) \wedge$ result' $\left(s, e, \pi_{2} * \mathrm{ARG}_{1}^{\text {result }}:\right.$ FROZEN $\left.\left.\left.)\right)\right)\right]$

$\left(\lambda P \lambda \pi^{\prime} \exists ! t\right.$. tea' $\left(t, \pi^{\prime} * \mathrm{ARG}_{1}^{t e a}:\right.$ LIQUID $\left.) \wedge P\left(\pi^{\prime}\right)(t)\right)=$ $\lambda \Phi \lambda e \lambda \pi \exists s . \Phi(\pi)\left(\lambda x \lambda \pi_{1} . \exists ! t\right.$. tea' $\left(t, \pi_{1} * \mathrm{ARG}_{3}^{\text {freeze }}: \mathrm{P} * \mathrm{ARG}_{1}^{\text {tea }}:\right.$ LIQUID $) \wedge$ freeze' $\left(e, x, t, \pi_{1} * \mathrm{ARG}_{1}^{\text {freeze }}: \mathrm{BECOME}\right) \wedge$ result' $\left(s, e, \pi_{1} * \mathrm{ARG}_{1}^{\text {result }}:\right.$ FROZEN $\left.)\right)$

b. $\quad$ den Tee einfrieren $\rrbracket(\llbracket$ das Mädchen $\rrbracket)=$ $\left[\lambda \Phi \lambda e \lambda \pi \exists s . \Phi(\pi)\left(\lambda x \lambda \pi_{1} . \exists ! t\right.\right.$. tea' $\left(t, \pi_{1} * \mathrm{ARG}_{3}^{\text {freeze }}: \mathrm{P} * \mathrm{ARG}_{1}^{\text {tea }}:\right.$ LIQUID $) \wedge$ freeze' $\left(e, x, t, \pi_{1} * \mathrm{ARG}_{1}^{\text {freeze }}: \mathrm{BECOME}\right) \wedge$ result' $\left(s, e, \pi_{1} * \mathrm{ARG}_{1}^{\text {result }}:\right.$ FROZEN $\left.\left.)\right)\right]$ $\left(\lambda Q \lambda \pi^{\prime} \exists ! g\right.$. girl' $\left.\left(g, \pi^{\prime}\right) \wedge \mathrm{Q}\left(\pi^{\prime}\right)(g)\right)=$ $\lambda e \lambda \pi \exists ! g \exists ! t \exists s$. girl' $(g, \pi) \wedge$ tea' $\left(t, \pi * \mathrm{ARG}_{3}^{\text {freeze }}: \mathrm{P} * \mathrm{ARG}_{1}^{\text {tea }}: \mathrm{LIQUID}\right) \wedge$ freeze' $\left(e, g, t, \pi * \mathrm{ARG}_{1}^{\text {freeze }}: \mathrm{BECOME}\right) \wedge$ result' $\left(s, e, \pi * \mathrm{ARG}_{1}^{\text {result }}:\right.$ FROZEN $)$ 


\section{c. Existential closure of $\boldsymbol{e}$ and binding presuppositions: \\ $\lambda \pi \exists ! g \exists ! t:$ LIQUID $\exists e: \operatorname{BECOME} \exists s:$ FROZEN. girl' $(g, \pi) \wedge$ tea' $(t, \pi) \wedge$ freeze' $(e, g, t, \pi) \wedge$ result' $^{\prime}(s, e, \pi)$}

When all arguments are integrated, the type presuppositions on the variables can be bound. This yields the meaning representation in (24c) for (23). There is exactly one $g$, exactly one $t$ of type LIQUID, an event $e$ of type BECOME and a state $s$ of type FROZEN such that $e$ is a freezing event where the girl $g$ freezes the tea $t$ and $s$ is the result of $e$.

\subsection{Abstract readings}

We have seen that the parallelism of the abstract reading of einfrieren to aspectual verbs like interrupt, German 'unterbrechen', is well motivated by the common entailment patterns in (7). Similarly, both unterbrechen and einfrieren combine with events that have a temporal extension (activities and accomplishments) while excluding states (25c) and achievements (25d).
a. Die Gewerkschaft hat die Gespräche unterbrochen / eingefroren. the union has the talks interrupted / in-frozen 'The union has interrupted / frozen the talks.'
b. Die Regierung hat den Straßenbau unterbrochen / eingefroren. the government has the road construction interrupted / in-frozen 'The government has interrupted / frozen the road construction.'
c. *Der Friseur hat das Schön-Sein unterbrochen / eingefroren. the hair dresser has the beautiful be interrupted / in-frozen 'The hair dresser has interrupted / frozen being beautiful.'
d. *Herr Schmidt hat das Ankommen des Zuges unterbrochen / eingefroren. $\mathrm{Mr} \quad$ Schmidt has the arriving of the train interrupted / in-frozen 'Mr Schmidt has interrupted / frozen the arriving of the train.'

These tests show that an eventive selectional restriction overgenerates, because einfrieren, like unterbrechen, only selects for temporally extended events in its complement position. We use the type label TRANSITION for these two Aktionsarten. German corpus data mirrors this generalization, because most of the complements we found were events with a temporal extension such as Siedlungstätigkeit and Friedensprozess. Formally, we model these combinatorial cases as standard compositions via functional application.

$$
\begin{aligned}
& \text {... wenn Israel seine Siedlungstätigkeit einfriere. } \\
& \ldots \text { if Israel its settlement activity freezes } \\
& \text { '... if Israel stops the settlement politics.' } \\
& \text { (Israel räumt Teil der Siedlungen, Die Presse, 14.10.1999) }
\end{aligned}
$$




\author{
Wenn man den Friedensprozess einfriert, verhindert man die Gründung eines \\ if one the peace process in-freezes, inhibits one the founding of a \\ palästinensischen Staates. \\ Palestinian state \\ 'Freezing the peace process inhibits the foundation of a Palestinian state.' \\ (Früchte des Zorns, Süddeutsche Zeitung, 27.10.2004)
}

However, corpus data from Spanish (Spalek, 2014) and German show that the combinatorial patterns are still more diverse. Value-denoting nouns, such as Eintrittspreise (28), abound in both languages. The interpretation of this example involves the inhibition of an increase in the prices.

(28) Bei soviel Preisstabilität in der Branche hat auch die Düsseldorfer Messe ihre with so much price stability in the branch has too the Düsseldorf trade fair its Eintrittspreise zum dritten Mal eingefroren. entry prices for the third time in-frozen

'Given the prices are stable in the branch, the Düsseldorf trade fair has frozen its entry prices for the third time.'

(Bei der weltgrößten Wassersportmesse “boot '91” können sich 400000 Interessenten auf 1800 Boote freuen, Nürnberger Nachrichten, 15.01.1991)

Example (28) with the value-denoting noun Eintrittspreise 'entry prices' also falls into the compositional class. Following Löbner (2015), we classify Eintrittspreise together with other value-denoting nouns such as temperature, which can receive a reading as a function from times to individual values. That is, it is inherent to values that they change over time. An indicator for the presence of this function is the fact that verbs like rising can be predicated over value-denoting nouns. Eintrittspreise and other value-denoting nouns we encountered with einfrieren also pass this test. ${ }^{9}$

A combinatorial pattern that does not straightforwardly fit the TRANSITION restriction is (29) with the state-denoting complement Punktestand. ${ }^{10}$ This might seem surprising given the tests in (25). Yet intuitively, the interpretation involves the inhibition of an expected change in the scores, in other words a transition.

d. h. der Punktestand wird eingefroren...

that means the score is in-frozen

'that means that the score is being frozen.'

(https://goo.gl/Mnv17X)

Interestingly, genuine Kimian states (Maienborn, 2005; Bücking, 2012), such as Schön-Sein, $\ddot{A}$ hneln and 60-Kilo-Wiegen in (30), are not appropriate complements of abstract einfrieren. The

\footnotetext{
${ }^{9}$ Note that we assume that value-denoting nouns actually have two readings: they can either denote a concrete value or a function from times to values. In TCL, this kind of ambiguity is encoded as a Dot-type; cf. the co-predication test The admission price is 20 Euros and rising every year.

${ }^{10}$ The German word Punktestand is overtly marked as a state by the second component of the compound. The English translation does not reflect that fact.
} 
reason for the ungrammaticality is that a presupposition of an inherent change is incompatible with the sortal properties of Kimian states. They are abstract entities without internal structure and lack potential for change. ${ }^{11}$

$$
\begin{aligned}
& \text { Man friert \#das Schön-Sein / \#das Ähneln / \#das 60-Kilo-Wiegen ein. } \\
& \text { one freezes the beautiful-being / the resembling / the 60-kg-weighing in } \\
& \text { 'One freezes the being beautiful / the resembling / the weighing } 60 \mathrm{~kg} \text {.' }
\end{aligned}
$$

We can thus formally assume that (29) involves a meaning enrichment through an interpolation of a transition based on Punktestand. What is interpolated here is the development of the scores over time. 'Freezing the scores' then means inhibiting any development in the value of the scores. We model this example as a coercion in TCL terms. This coercion is possible within well-defined boundaries: only Davidsonian States can be coerced into events. Abstract einfrieren thus displays a similar behaviour to aspectual verbs, which are well known for their eventive selectional restriction and their ability to license a coercion from complements of other types to events (Pustejovsky, 1995; Egg, 2003; Asher, 2011).

Now that the combinatorial options in the abstract reading have been clarified, we turn to the properties of the result state brought about by abstract einfrieren. In the previous subsection, we argued that the result state of the physical reading is tripartite and comprises the properties of having a temperature below zero, being solid and being preserved. Of these three properties, only one is not restricted to the physical domain, namely the property of being preserved. Both physical objects and states of affairs as part of a transition can be preserved. This property functions as a conceptual bridge from the physical to the abstract reading. The other two component parts of physical freezing are omitted in the abstract reading.

We now have all ingredients to propose a meaning representation for the abstract reading. Our proposal has three central features. First, abstract einfrieren requires its complement to be of type TRANSITION. Second, in this argument position, coercion is lexically licensed. In order to model this, we integrate a polymorphic $\tau \rho$ type into the type presupposition for the complement. It licenses a coercion in complement position if the selectional restriction is not met. The basis for complement coercion is restricted. Abstract einfrieren determines that only states are a suitable type from which transitions can be interpolated. Third, the result state FROZEN corresponds to the property of being preserved in the abstract reading.

$$
\begin{aligned}
& \text { 【einfrieren } a \rrbracket=\lambda \Psi \lambda \Phi \lambda e \lambda \pi \exists s . \Phi(\pi)\left(\lambda x \lambda \pi_{1} . \Psi\left(\pi_{1} * \mathrm{ARG}_{3}^{\text {freeze }}\right. \text { :TRANSITION- }\right. \\
& \tau \rho(\mathrm{HD}(\Psi) \sqsubseteq \mathrm{STATE}))\left(\lambda y \lambda \pi_{2} \text {.freeze' }\left(e, x, y, \pi_{2} * \mathrm{ARG}_{1}^{\text {freeze }}:{\mathrm{BECOME} * \mathrm{ARG}_{1}^{\Psi}: \mathrm{TY}}^{P S}(\Psi)\right) \wedge\right. \\
& \text { result' } \left.\left.\left(s, e, \pi_{2} * \mathrm{ARG}_{1}^{\text {result }}: \text { FROZEN }\right)\right)\right)
\end{aligned}
$$

Abstract einfrieren has the same external semantics as the physical reading. It takes two

${ }^{11}$ In contrast, tropes in the sense of Moltmann (2013) as inherently changing entities are acceptable complements of einfrieren (i).

(i) Man friert die Schönheit / die Ähnlichkeit / das Gewicht ein.

one freezes the beauty / the resemblance / the weight in

'One freezes the beauty / the resemblance / the weight.'

Tropes are concrete property manifestations on a holder; cf. Moltmann (2013). 
generalized quantifiers ( $\Psi$ and $\Phi$ ) and an event argument $e$ and introduces an existentially bound state argument $s$. It contributes a freeze'-predicate and a state that is the result of the freezing event. Abstract and physical readings differ only in their internal semantics. The complement is restricted to being of type TRANSITION. Furthermore, abstract einfrieren features a polymorphic type for coercions from states to transitions. The meaning computation for a compositional abstract reading thus follows the line of the physical variant in (24).

In (34), we give the meaning computation for the coercion-case in (32): einfrieren is applied to the state-denoting complement Punktestand, which does not satisfy the verb's selectional restriction transition. In order to repair the conflict, the interpolation of a suitable argument is licensed by the polymorphic type $\tau \rho$. The polymorphic type licenses coercion only if the given complement is of STATE type. This restriction is met by Punktestand and the coercion operation can proceed.

$$
\begin{aligned}
& \text { Der Organisator fror den Punktestand ein. } \\
& \text { the organizers froze the score in } \\
& \text { 'The organizers froze the score.' }
\end{aligned}
$$

In (34a), abstract einfrieren is applied to the DP den Punktestand 'the score', which has the referential variable $c$ in our representation. This variable is typed as STATE. The required type for the third argument of freeze is TRANSITION. With this typing information, a conflict on the variable $c$ arises. As abstract einfrieren features a polymorphic type, the type presupposition can be accommodated by interpolating a suitable argument of TRANSITION type. The coercion functor in (34b) is a deduction from the polymorphic type based on the TCL rule for type accommodations with polymorphic types, see (33).

$$
\begin{aligned}
& \text { Type Accommodation with Polymorphic Types (Asher, 2011: p. 225): } \\
& \frac{\phi(v, \pi) \quad \pi \text { carries } \operatorname{ARG}_{i}^{P}: \delta(\alpha, \beta) * \mathrm{ARG}_{j}^{Q} \alpha / \beta \quad v \in \mathrm{ARG}_{i}^{P} \cap \mathrm{ARG}_{j}^{Q}}{\mathscr{D}\left(\lambda w \lambda \pi_{1} . \phi\left(w, \pi_{1}\right)\right)(\pi)(v)}
\end{aligned}
$$

The functor introduces the variable $e_{1}$ that is a transition depending on the score. This dependency is expressed by the type information on $e_{1}$. It has to be of type $\tau \rho$ (SCORE), which is a very specific type of transition, namely one that is a transition of scores. Typically, coercion functors in TCL introduce an underspecified predicate $\phi$ that requires contextual specification. This predicate relates the newly introduced variable $e_{1}$ to the original state argument $c$. The underspecification of the predicate gives us the possibility to determine a concrete transition in the given context.

In (34c), the result of the application of the coercion functor is given. The freeze'-predicate now has $e_{1}$ as its third argument. This variable meets the type requirements on the complement of abstract einfrieren. Nevertheless, the original state variable $c$ is still present in the meaning representation and it has kept its original type. That is, the score-DP itself is still intact. The conflict has been solved locally in the nuclear scope of the quantifier, which is characteristic for TCL-style coercions. ${ }^{12}$ In (34d), the subject argument is integrated via regular functional

\footnotetext{
${ }^{12}$ Although Asher (2011) gives a series of reasons why coercion should be local, computationally the locality has to
} 
application.

a. $\quad$ einfrieren $\rrbracket(\llbracket$ den Punktestand $\rrbracket)=$

$\left[\lambda \Psi \lambda \Phi \lambda e \lambda \pi \exists s . \Phi(\pi)\left(\lambda x \lambda \pi_{1} . \Psi\left(\pi_{1} * \mathrm{ARG}_{3}^{\text {freeze }}\right.\right.\right.$ :TRANSITION-

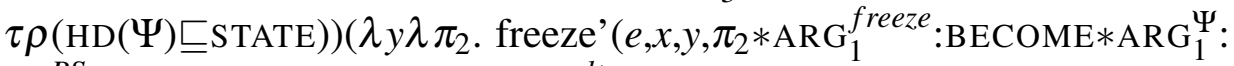

$\left.\mathrm{TY}^{P S}(\Psi)\right) \wedge$ result' $\left(s, e, \pi_{2} * \mathrm{ARG}_{1}^{\text {result }}:\right.$ FROZEN $\left.\left.\left.)\right)\right)\right]$

$\left(\lambda P \lambda \pi^{\prime} \exists ! c\right.$. score' $\left.\left(c, \pi^{\prime} * \mathrm{ARG}_{1}^{\text {score }}: \mathrm{STATE}\right) \wedge P\left(\pi^{\prime}\right)(c)\right)=$

$\lambda \Phi \lambda e \lambda \pi \exists s . \Phi(\pi)\left(\lambda x \lambda \pi_{1} \exists ! c\right.$. score' $\left(c, \pi_{1}\right) \wedge$ freeze' $\left(e, x, c, \pi_{1}\right.$

$* \mathrm{ARG}_{1}^{\text {freeze }}: \mathrm{BECOME} * \mathrm{ARG}_{1}^{\text {score }}: \mathrm{STATE} * \mathrm{ARG}_{3}^{\text {freeze }}:$ TRANSITION- $\left.\tau \rho(\mathrm{SCORE})\right) \wedge$

result' $\left(s, e, \pi_{1} * \mathrm{ARG}_{1}^{\text {result }}:\right.$ FROZEN $\left.)\right)$

b. Coercion functor:

$\lambda P \lambda z \lambda \pi^{\prime} \exists e_{1}: \tau \rho$ (SCORE). $P\left(\pi^{\prime}\right)\left(e_{1}\right) \wedge \phi_{\tau \rho(\text { score })}\left(e_{1}, \ldots, z, \pi^{\prime}\right)$

c. Local conflict resolution via coercion functor:

$\lambda \Phi \lambda e \lambda \pi \exists s \exists e_{1}: \tau \rho$ (SCORE). $\Phi(\pi)\left(\lambda x \lambda \pi_{1} \exists ! c\right.$. score' $\left(c, \pi_{1}\right) \wedge$ freeze' $\left(e, x, e_{1}, \pi_{1}\right.$

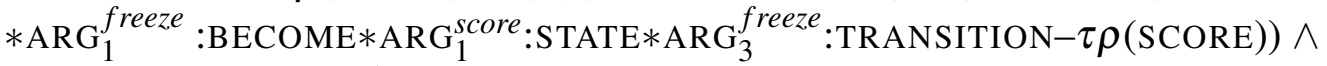

result' $\left(s, e, \pi_{1} * \mathrm{ARG}_{1}^{\text {result }}:\right.$ FROZEN $\left.) \wedge \phi_{\tau \rho(\text { score })}\left(e_{1}, \ldots, c, \pi_{1}\right)\right)$

d. den Punktestand einfrieren $\rrbracket(\llbracket$ der Organisator $\rrbracket)=$

$\lambda e \lambda \pi \exists ! o \exists ! c \exists s \exists e_{1}: \tau \rho$ (SCORE). organizer' $(o, \pi) \wedge$ score' $^{\prime}(c, \pi) \wedge$ freeze' $\left(e, o, e_{1}, \pi\right.$ $* \mathrm{ARG}_{1}^{\text {freeze }}: \mathrm{BECOME} * \mathrm{ARG}_{1}^{\text {score }}: \mathrm{STATE} * \mathrm{ARG}_{3}^{\text {freeze }}:$ TRANSITION- $\left.\tau \rho(\mathrm{SCORE})\right) \wedge$ result' $\left(s, e, \pi * \mathrm{ARG}_{1}^{\text {result }}: \mathrm{FROZEN}\right) \wedge \phi_{\tau \rho(\text { score })}\left(e_{1}, \ldots, c, \pi\right)$

e. Existential closure of $e$ and binding presuppositions:

$\lambda \pi \exists ! o \exists ! c: \operatorname{STATE} \exists e: \operatorname{BECOME} \exists s: \operatorname{FROZEN} \exists e_{1}: \tau \rho(\operatorname{SCORE})$. organizer' $(o, \pi) \wedge$ $\operatorname{score}^{\prime}(c, \pi) \wedge$ freeze' $\left(e, o, e_{1}, \pi\right) \wedge \operatorname{result}^{\prime}(s, e, \pi) \wedge \phi_{\tau \rho(\text { score })}\left(e_{1}, \ldots, c, \pi\right)$

In (34e), we give the final meaning representation for (32). There is exactly one $o$, exactly one $c$ of type STATE, an $e$ of type BECOME, an $s$ of type FROZEN and an $e_{1}$ of a TRANSITION type depending on scores such that the organizer $o$ freezes an underspecified transition $e_{1}$ that is related to the score $c$ and the FROZEN type state $s$ is the result of $e$. The underspecified transition predicate $\phi_{\tau \rho(\text { score })}$ is still to be specified. The specification of this predicate hinges on contextual information, but is restricted to transitions that have scores as an argument. One specification for this transition could be an increase in the scores.

\section{An integrated lexical semantics for physical and abstract readings}

So far, we have developed two separate lexical entries for the physical and the abstract readings. In this section, we will discuss the pros and cons of a unified lexical semantics for both readings of einfrieren and make a proposal for its implementation in TCL.

The discreteness of the two readings seems to be a good reason to argue for two independent

be stipulated, i.e. the relevant type information from the $\pi$-parameter in the complement quantifier's restrictor has to be copied into the nuclear scope, where it can be adapted locally. In order to anchor this operation lexically and avoid a pure stipulation, we use the type function $\mathrm{ARG}_{1}^{\Psi}: \mathrm{ARG}^{P S}(\Psi)$ in our lexical entries, which systematically transfers the relevant type information to the right place and thus designates the coercion as local. This method gains additional support from the fact that there are coercion phenomena where the operation is not local and has to be lexically designated as global (Bücking and Buscher, 2015). 
lexical entries for einfrieren: physical freezing means lowering the temperature and abstract freezing means interrupting an ongoing event. More precisely, we have observed that the two readings bring about different result states and belong to different aspectual classes. Whereas physical einfrieren is an accomplishment, abstract einfrieren patterns with achievements. With this in mind, the assumption of two independent lexical entries has some initial motivation. However, postulating two independent lexical entries for einfrieren would miss the conceptual relation between the two readings. Physical and abstract einfrieren share the conceptual core PRESERVED. This component represents the conceptual bridge that allows for the transfer from the physical domain to the abstract domain. Furthermore, this kind of ambiguity between physical and abstract change of state events is very systematic. We have seen that the ambiguity occurs with different $\mathrm{CoS}$ verbs, too. Moreover, it is parallel across languages; cf. Spanish congelar, English freeze, French geler and Polish zamrażać/zamrozić, to name just the languages we have intuitions for. We would disregard a systematic lexical pattern if we considered the ambiguity to be a case of homonymy. We take these observations to be arguments enough for a unified lexical semantics for both readings of einfrieren. This lexical entry has to be semantically adaptable to different types of argument input. The combination of the lexical semantics of the verb with the semantics of the complement will tell us which inferences to draw in each case.

Our proposal for a unified semantics of the CoS verb einfrieren builds on the common assumption that $\mathrm{CoS}$ verbs have the underlying class-specific lexical template BECOME and differ in the idiosyncratic result state. ${ }^{13}$ The unified lexical semantics for einfrieren is given in (35). It uses both a coercion and an underspecification mechanism. The two mechanisms have a lexical anchor in the internal semantics of einfrieren. Underspecification accounts for the dichotomy between physical and abstract readings, and we model it as a dependent type. Dependent types are complex types that are already envisaged within TCL. A type qualifies as a dependent type if it has another type as its parameter. We use a dependent FROZEN-type with the complement's type as its parameter for the result state of einfrieren. This means that the actual type of the result state is assigned only upon combination with the complement. The type assignment is driven by the general type FROZEN in (35b). If the parameter is a physical object, FROZEN will be specified to the tripartite type SOLID $\wedge$ TEMP $<0 \wedge$ PRESERVED. If the parameter is a transition, the general type FROZEN yields a specification to PRESERVED. These two parameter types are the only types that are lexically licensed. This is provided for by the type presupposition on the complement. It allows exclusively physical objects or transitions.

The combinatorial peculiarities we identified in the abstract reading are modelled along the lines proposed for coercion in Asher (2011). The lexical entry features a polymorphic type for the complement position. This polymorphic type comes into play in well-defined cases. If the overt complement does not justify the selectional restriction, the compositional conflict can be repaired if the overt argument is a state. The polymorphic type then licenses the interpolation of a TRANSITION type argument. This newly introduced argument justifies the selected TRANSITION type in the complement position. The coercion operation is lexically determined to be local and non-destructive, i.e. the conflict resolution does not change the type of the complement DP itself.

\footnotetext{
${ }^{13}$ We represent the CoS via the type BECOME for the referential argument. BECOME is underspecified with regard to the exact aspectual class; see Dowty (1979).
} 


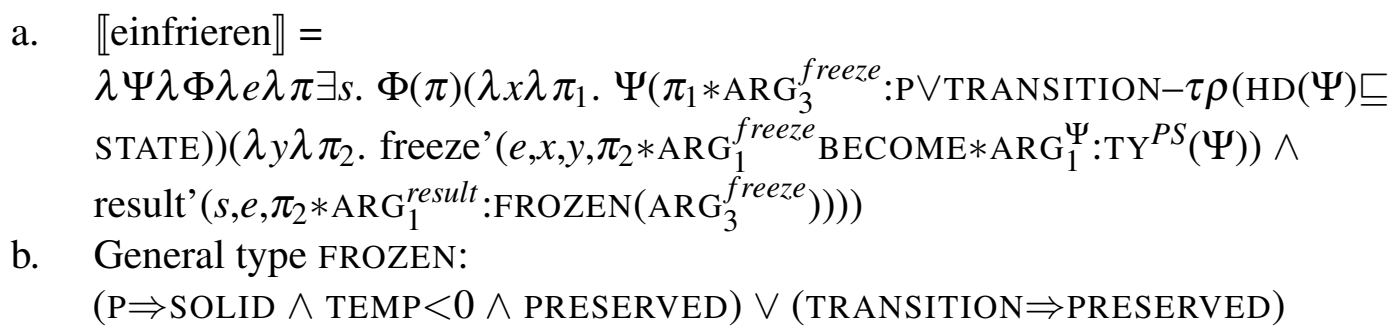

The difference between underspecification and coercion is visible on the type level, i.e. in the internal semantics. Underspecification is modelled as a dependent type and coercion as a polymorphic type. Whereas dependent types are types of some variable that is already present in the representation and whose specification hinges on the type of their parameter, polymorphic types are types of a variable that has to be interpolated depending on the parameter in order to satisfy the selectional restrictions of the functor featuring the polymorphic type. With this formal representation of underspecification and coercion, we mirror well-established conceptions of these two mechanisms. Other authors (Piñango and Deo, 2016; Egg, 2003; Dölling, 2003) understand underspecification as a semantically foreseen slot for contextual enrichment. In our account, dependent types do the same job on the type level: they systematically provide a semantic slot for contextual specification. The advantage of using dependent types is that we do not introduce variables that might end up being reduced to the identity function. Coercion is commonly understood as a repair mechanism for combinatorial conflicts that results in the introduction of a new variable only if it is necessary; cf. Pustejovsky (1995), de Swart (2011) and Asher (2011). Our TCL-style coercion functor fulfils the same task. However, none of the cited accounts treats these two mechanisms as measures to model different sorts of phenomena. They are usually treated as mutually exclusive alternatives. Our account integrates these two mechanisms into one system and does it on linguistically well-established grounds.

\section{Summary}

We have presented a case study of a wide-spread phenomenon in predication that shows that combinatorial adaptability is almost ubiquitous. With this case study, we have illustrated that even the most mundane composition requires both underspecification and coercion. In our account, underspecification is modelled in terms of a dependent type that receives a specification upon the combination of functor and argument, ${ }^{14}$ whereas coercion is modelled in terms of a polymorphic type that resolves compositional conflicts by introducing an additional variable.

\section{References}

Apresjan, J. (1974). Regular polysemy. Linguistics 12(142), 5-32.

Asher, N. (2011). Lexical Meaning in Context. A Web of Words. Cambridge: Cambridge University Press.

Asher, N., M. Abrusan, and T. Van de Cruys (2017). Types, meanings and co-composition in lexical semantics. In Z. Luo and S. Chatzikyriakidis (Eds.), Modern Perspectives in TypeTheoretical Semantics, Number 98 in Studies in Linguistics and Philosophy, pp. 135-161.

\footnotetext{
${ }^{14}$ Other approaches have discussed similar ideas under the label co-composition; cf. Pustejovsky (1995) and Asher et al. (2017).
} 
Berlin: Springer.

Bücking, S. (2012). Müdigkeit und Müde-Sein: Zur Semantik adjektivbasierter Zustandsnominalisierungen im Deutschen. Linguistische Berichte 232, 361-397.

Bücking, S. and F. Buscher (2015). Stative locative alternations as type coercion. In U. Steindl, T. Borer, H. Fang, A. Garcia Pardo, P. Guekguezian, B. Hsu, C. O'Hara, and I. C. Ouyang (Eds.), Proceedings of the 32nd West Coast Conference on Formal Linguistics, pp. 92-102.

de Swart, H. (2011). Mismatches and coercion. In C. Maienborn, K. Von Heusinger, and P. Portner (Eds.), Semantics: An International Handbook of Natural Language Meaning (HSK ed.), Volume 33(1), pp. 574-597. Berlin: Walter de Gruyter.

Dölling, J. (2003). Flexibility in adverbal modification: Reinterpretation as contextual enrichment. In E. Lang, C. Maienborn, and C. Fabricius-Hansen (Eds.), Modifying Adjuncts, pp. 511-525. Berlin: de Gruyter.

Dowty, D. R. (1979). Word Meaning and Montague Grammar. The Semantics of Verbs and Times in Generative Semantics and in Montague's PTQ. Dordrecht: Kluwer.

Egg, M. (2003). Beginning novels and finishing hamburgers: Remarks on the semantics of to begin. Journal of Semantics 20, 163-191.

Engerer, V. (2014). Phases in verbal semantics. In K. Robering (Ed.), Events, Arguments, and Aspects, pp. 227-260. Berlin and Amsterdam: Benjamins.

Koontz-Garboden, A. (2009). Anticausativization. Natural Language and Linguistic Theory 27, 77-138.

Levin, B. (1993). English Verb Classes and Alternations. A Preliminary Investigation. Chicago: The University of Chicago Press.

Levin, B. and M. Rappaport Hovav (1995). Unaccusativity: At the Syntax-Lexical Semantics Interface. Cambridge, Massachusetts: MIT Press.

Löbner, S. (2015). Functional concepts and frames. In T. Gamerschlag, D. Gerland, R. Osswald, and W. Petersen (Eds.), Meaning, Frames, and Conceptual Representation, pp. 15-42. Düsseldorf: Düsseldorf University Press.

Lukassek, J. (2015). A single-event analysis for German eventive mit-modifiers. In H. Zeijlstra and E. Csipak (Eds.), Proceedings of SuB 19, pp. 375-392.

Lukassek, J. and A. A. Spalek (2016, 04-07 March). Underspecification and coercion: Where conceptual knowledge meets compositional semantics. Handout.

Maienborn, C. (2005). On the limits of the Neo-Davidsonian approach: The case of copula sentences. Theoretical Linguistics 31, 275-316.

Moltmann, F. (2013). On the distinction between abstract states, concrete states, and tropes. In C. Beyssade, A. Mari, and F. del Prete (Eds.), Genericity, pp. 293-311. Oxford: Oxford University Press.

Piñango, M. M. and A. Deo (2016). Reanalyzing the complement coercion effect through a generalized lexical semantics for aspectual verbs. Journal of Semantics 33, 359-408.

Pustejovsky, J. (1995). The Generative Lexicon. Cambridge, Massachusetts: MIT Press.

Spalek, A. (2014). Verb Meaning and Combinatory Semantics: A Corpus-Based Study of Spanish Change of State Verbs. Ph. D. thesis, UPF, Barcelona.

Wright, S. K. (2002). Transitivity and change of state. In Annual Meeting of the Berkeley Linguistics Society, Volume 28, pp. 339-350. 